\title{
CARACTERÍSTICAS DOS PENDÕES E DO PÓLEN DE HÍBRIDOS CONVENCIONAIS E TRANSGÊNICOS DE MILHO (Zea mays l.), E SEU EFEITO SOBRE O COMPARTAMENTO FORRAGEIRO DE ABELHAS Apis mellifera
}

\author{
VINHA, Fernando Belezini ${ }^{1}$ \\ SOARES, Daniela Fagotti ${ }^{2}$ \\ MALERBO-SOUZA, Darclet Teresinha ${ }^{3}$
}

\begin{abstract}
RESUMO: Este experimento foi conduzido em Ribeirão Preto, SP, Brasil e teve como objetivo identificar as características dos pendões dos híbridos convencionais e transgênicos de milho (Zea mays) que influenciam a visitação das abelhas Apis mellifera africanizadas na coleta de pólen. Para isso, uma área foi plantada com um híbrido convencional e seis híbridos transgênicos de milho (Powercore®, YG VT Pro®, Viptera®, Viptera 3®, Optimum Intrasect ${ }^{\circledR}$ e Herculex HR $\left.®\right)$, o delineamento do experimento foi em blocos casualizados em uma área de $27 \mathrm{~m} \times 12 \mathrm{~m}$, sendo utilizado $3 \times 3$ metros para cada híbrido, com quatro repetições, em duas épocas de plantio. A frequência das abelhas nas flores foi avaliada por meio de contagens das $7 \mathrm{~h} 00$ às $11 \mathrm{~h} 00$, cinco minutos em cada horário, com cinco repetições (dias distintos), no período de florescimento da cultura. Os pendões de cada híbrido foram avaliados com relação às características morfológicas (comprimento e largura). Além disso, 10 pendões de cada híbrido foram coletados e o pólen foi recolhido e armazenado para posterior análise da proteína bruta. O florescimento ocorreu em janeiro ( $1^{\circ}$. Plantio) e em abril de 2014 ( $2^{\circ}$. Plantio). As abelhas visitaram os pendões, preferencialmente, entre $7 \mathrm{~h} 00$ e $8 \mathrm{~h} 00$, para coleta exclusiva de pólen. O híbrido Viptera apresentou o polém com maior teor de proteína bruta, sendo um dos híbridos mais visitados, no segundo plantio, entretanto, as abelhas apresentaram diferenças na preferência nos dois plantios realizados.
\end{abstract}

Palavras-chave: Polinização. Híbridos. Forrageamento. Néctar.

\section{TASSELS AND POLLEN CHARACTERISTICS OF CONVENTIONAL AND TRANSGENIC MAIZE (Zea mays l.) HYBRIDS, AND ITS EFFECT ON HONEYBEES Apis mellifera FORAGE BEHAVIOR}

\begin{abstract}
SUMMARY: The experiment was conducted in Ribeirão Preto,SP, Brazil. Our goal was to identify the characteristics of the tassels of conventional and transgenic corn hybrids (Zea mays) that influence the visitation of Africanized bees during pollen collection. For this conventional hybrid and six transgenic corn hybrids (Powercore ${ }^{\circledR}$, YG VT Pro®, Viptera ${ }^{\circledR}$, Viptera $3 \AA$, Optimum Intrasect ${ }^{\circledR}$ and Herculex HR®) were planted in an area of $27 \mathrm{x} 12 \mathrm{~m}$, $3 \times 3$ meters being used for each hybrid with four replications and the experimental design was in randomized blocks. The frequency of the bees in the flowers was assessed by counting from 7:00 to 12:00, five minutes each time, with four replicates (different days), during the flowering period of the crop. Morphological characteristics (length and diameter) from each hybrid banners were evaluated. In addition, 10 of each hybrid tassels and its pollen was collected and stored for crude protein analysis. The flowering occurred in 2014 January (First planting) and April (Second planting). The bees visited the banners, preferably between 7:00 and 8:00 a.m. exclusively for pollen collection. The hybrid Viptera had the highest pollen crude protein content, being one of the most popular hybrid, in the second planting. However, the bees showed differences in preference in the two maize plantations.
\end{abstract}

Keywords: Pollination. Hybrids. Foraging. Nectar.

\footnotetext{
${ }^{1}$ Graduado em Agronomia no CUML, Mestre em Entomologia pela ESALQ-USP.

${ }^{2}$ Graduada em Zootecnia pela UNESP-FCAV, Mestranda em produção animal sustentável no Instituto de Zootecnia (IZ)

${ }^{3}$ Graduação em Zootecnia FCAVJ/UNESP, Mestrado em Entomologia pela FFCLRP/USP. Doutorado em Zootecnia pela FCAVJ/UNESP. Foi professora na FAFRAM,CUML,FCAVJ/UNESP.
} 


\section{INTRODUÇÃO}

Uma das características das abelhas é a dependência integral de produtos florais, principalmente de néctar e pólen, para a sua alimentação e como provisão para as suas crias. O pólen coletado das anteras de flores é essencial para a nutrição de abelhas, provendo recurso de proteína principalmente para larvas e adultos, além disso, o consumo de pólen pelas abelhas adultas é fundamental para a produção de geleia real (NOGUEIRA-COUTO, COUTO, 2006).

Uma das fontes utilizadas pelas abelhas para coleta exclusiva de pólen é o milho (Zea mays L.). Os pendões do milho são intensamente visitados pelas abelhas A. mellifera africanizadas (GONÇALVES, 2009; ROSA NETO, 2010). Apesar de não conter teores altos de proteína bruta, em torno de $15 \%$ (WIESE, 2005), esse recurso alimentar é importante para essas abelhas porque floresce em épocas de escassez de alimento.

Entretanto, o pólen coletado pelas abelhas pode estar contaminado com agroquímicos que podem afetar diretamente as abelhas ou indiretamente, quando transportados para a colônia, afetando o desenvolvimento de crias e contaminando o pólen armazenado nos alvéolos.

Além disso, é recente a preocupação com a coleta de pólen de híbridos transgênicos, em especial do milho, e seus efeitos, tanto para as abelhas quanto para os seres humanos.

O Brasil é o terceiro maior produtor de milho no mundo, e o grão representa aproximadamente $40 \%$ de toda a safra brasileira de grãos. A utilização de sementes geneticamente modificadas de milho cresceu bastante nos últimos anos, de acordo com o Serviço Internacional para Aquisição de Aplicações em Agrobiotecnologia (ISAAA), em 2016 plantou-se um total de 5,3 milhões de hectares de milho geneticamente modificado. O número representa $88 \%$ do total semeado com a cultura nas duas safras (verão e inverno) (ISAAA,2016).

A elevação da produtividade, o melhor combate de pragas e aumento da oferta de variedades são alguns dos fatores que estimulam a adoção da tecnologia. De acordo com Miyamoto (2012), o milho é uma planta alta, o que torna a aplicação de inseticidas complicada, sendo que com o grão transgênico, o manejo ficou mais fácil.

Arpaia et al. (2006) relacionaram alguns testes que deveriam ser realizados para avaliar o efeito dos transgênicos sobre as abelhas, enfatizando testes sobre a atratividade desses híbridos para as abelhas e seus efeitos na atividade de coleta e, no consequente desenvolvimento da colônia.

Devido a esses motivos, os objetivos do presente trabalho foram avaliar as características dos pendões e do pólen de híbridos convencionais e transgênicos de milho (Zea mays L.), e seu efeito sobre o comportamento forrageiro de abelhas Apis mellifera africanizadas, em condições de campo.

\section{MATERIAL E MÉTODO}

O presente experimento foi conduzido na área experimental do campus do Centro Universitário Moura Lacerda (CUML), em Ribeirão Preto, SP, cuja altitude é de 620 metros, com as seguintes

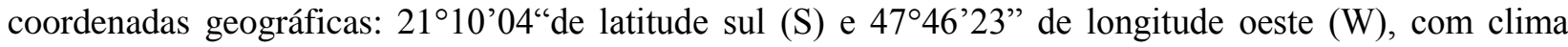
subtropical temperado e temperatura média anual ao redor de $21^{\circ} \mathrm{C}$ e média de precipitação pluviométrica anual é $1.500 \mathrm{~mm}$. 
$\mathrm{Na}$ área estudada, o milho sempre é plantado na safra (outubro/novembro) e na safrinha (janeiro a abril). Essa continuidade de área plantada fornece pólen em abundância e se torna uma excelente alternativa de fonte de proteína para as colmeias próximas.

A Instituição possui um apiário com oito colmeias de abelhas Apis mellifera africanizadas, situadas próximas à área de cultivo, onde foi realizado o experimento.

O experimento de campo teve as semeaduras realizadas nos dias 23/11/2013 e 06/02/2014, com espaçamento de $0,7 \mathrm{~m}$ entre linhas e mantendo. $O$ delineamento do experimento foi em blocos casualizados, onde sete tratamentos foram repetidos quatro vezes, em parcelas experimentais de 4,2 (6 linhas) x 6,0 m (25,2 m2), sendo mantidas bordaduras de 0,70 m mantidas no limpo (Figura 1). Foi realizada uma adubação de cobertura com sulfato de amônio do equivalente a $500 \mathrm{Kg}$ ha-1 (06/01/2014) na primeira data de plantio e as plantas daninhas foram controladas com o herbicida 2,4diclorofenoxiacético (2,4-D), nas datas de plantio.

Os genótipos utilizados foram: (1) milho convencional 2B587 (testemunha, sem controle); (2) milho transgênico expressando os genes Cry1F + pat + Cry1A105 + Cry2Ab2 + EPSPS (2B587, PowerCore $\left.{ }^{\circledR}\right)$; (3) Cry1A105 + Cry2Ab2 (DKB 390, YieldGard VT PRO®); (4) Vip3A + pmi (Status, Agrisure Viptera $\left.{ }^{\circledR}\right) ;(5)$ Vip3A + Cry1 Ab + EPSPS + pmi (Maximus, Agrisure Viptera 3®); (6) Cry1F + pat (2B587, Herculex®); (7) Cry1Ab + Cry1F + EPSPS + Pat (30F53, Optimum Intrasect $\left.{ }^{\circledR}\right)$.

A frequência das visitações das abelhas africanizadas, coletando pólen, no decorrer do dia, foi obtida por contagem, nos primeiros cinco minutos de cada horário, das 7 h00 às 11 horas, com três repetições (três dias distintos), em cada híbrido.

Esses dados foram obtidos percorrendo o interior da cultura, evitando-se assim as áreas de bordadura, durante cinco minutos em cada horário e em cada híbrido (7h00 às 7h05 no híbrido 1, 7h05 às 7 h10 no híbrido 2 . 7h10 às 7 h 15 no híbrido 3 e das 7 h15 às 7 h20 no híbrido 4,7 h20 às 7 h 25 no híbrido 5 , 7 h25 às 7 h30 no híbrido 6 e 7 h30 às 7 h35 no híbrido 7, e assim, sucessivamente até às $11 \mathrm{~h} 00$ ). Nessas avaliações, foi anotado o número de abelhas africanizadas coletando pólen nos pendões do milho, em cada híbrido.

Figura 1. Croqui da área experimental com os diferentes híbridos de milho Zea mays, em Ribeirão Preto, SP, em plantio safrinha.

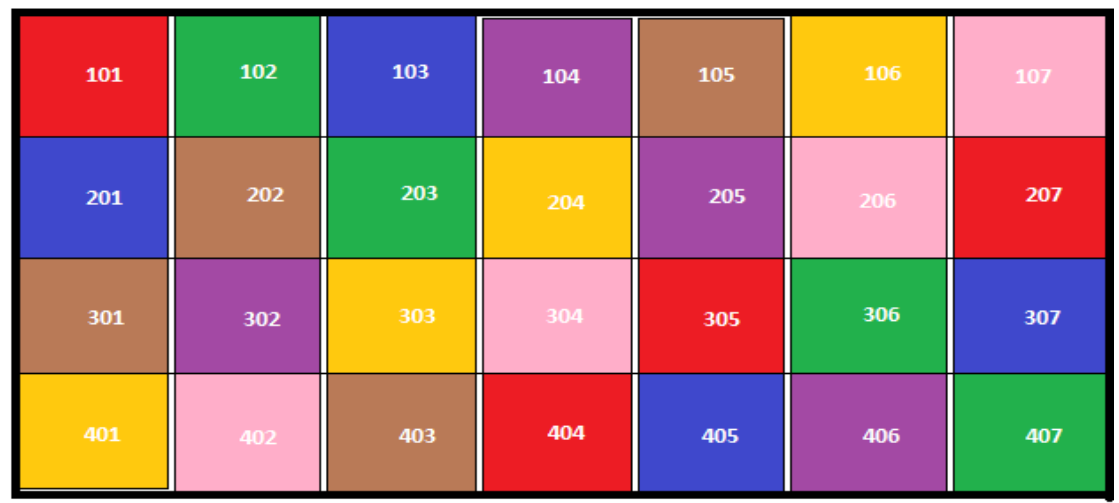

Fonte: Dados da pesquisa. 


\section{Legenda:}

\begin{tabular}{|c|c|c|}
\hline Milho & & Parcelas \\
\hline Vermelho: & POWERCORE & $101,207,305,404$ \\
\hline Verde: & YG VT PRO & $102,203,306,407$ \\
\hline Azul: & VIPTERA & $103,201,307,405$ \\
\hline Violeta: & VIPTERA 3 & $104,205,302,406$ \\
\hline \multirow[t]{2}{*}{ Marrom: } & OPTIMUM & $105,202,301,403$ \\
\hline & INTRASECT & \\
\hline Amarelo: & HERCULEX HR & $106,204,303,401$ \\
\hline Rosa: & CONVENCIONAL & $107,206,304,402$ \\
\hline
\end{tabular}

Para avaliar a composição do pólen coletado pelas abelhas, 10 pendões de cada híbrido foram coletados, com duas repetições, totalizando 20 pendões para cada híbrido. O pólen foi separado das espiguetas por meio de peneiras individualizadas para cada híbrido $\mathrm{O}$ pólen retirado dos pendões de cada híbrido foi etiquetado e mantido refrigerado para posterior análise de proteína bruta. Duas lâminas de cada híbrido foram confeccionadas para identificar diferenças na estrutura dos grãos de pólen.

Além disso, um ninho composto de dez quadros foi instalado próximo à área experimental. Em cinco dias (cinco repetições), com intervalos de três dias, foi colocado um extrator de pólen no alvado desse ninho, sendo que o extrator permaneceu, por um período de 12 horas, das 6 h00 às $18 \mathrm{~h} 00$. Posteriormente, essas amostras de pólen, tanto coletadas diretamente dos pendões quanto as coletadas do extrator, foram armazenadas em refrigerador, devidamente etiquetados, para posterior análise com relação à proteína bruta.

Lâminas contendo um mix das amostras do pólen, coletado dos extratores, foi preparada e analisada em microscópio com relação a quantidade de pólen de milho utilizado pelas abelhas em relação à outras fontes de pólen, presentes na área experimental.

Também foram avaliados o comprimento, largura e a forma estrutural de pendões de cada híbrido, com 10 repetições.

As análises estatísticas foram processadas utilizando o software Statistical Analysis System procedimento de regressão (SAS, 2013). Foi utilizado o teste de Tukey para comparação de médias dos tratamentos.

\section{RESULTADO E DISCUSSÃO}

Os dados do primeiro plantio foram coletados entre os dias 24 a 28 de janeiro de 2014.

Foram observadas, principalmente, abelhas A. mellifera africanizadas nos pendões do milho. Entretanto, algumas outras espécies de abelhas nativas foram observadas esporadicamente.

As abelhas visitaram os pendões apenas entre $7 \mathrm{~h} 00$ e $11 \mathrm{~h} 00$, com pico de frequência às $7 \mathrm{~h} 00$ (Tabela 1).

Com relação aos híbridos, no primeiro plantio, observou-se que o convencional foi mais visitado pelas abelhas africanizadas, sendo significativamente superior apenas ao híbrido YG VT PRO® (Tabela $1)$. 
Tabela 1. Número médio de abelhas Apis mellifera africanizadas, coletando pólen, das 7h00 às $11 \mathrm{~h} 00$, nos pendões de diferentes híbridos de milho (Zea mays), em Ribeirão Preto,2014.

\begin{tabular}{l|c|c|c|c|c|c|c|c}
\hline Horário & Powercore & Viptera & Optimum & Herculex & $\begin{array}{c}\text { YG VT } \\
\text { PRO }\end{array}$ & Viptera 3 & Convencional & Média \\
\hline $7 \mathrm{~h} 00$ & 0 & 10 & 6 & 6 & 2 & 10 & 15 & $\mathrm{a}$ \\
\hline $8 \mathrm{~h} 00$ & 4 & 4 & 0 & 2,5 & 0 & 0,5 & 11 & $\mathrm{ab}$ \\
\hline $9 \mathrm{~h} 00$ & 1,5 & 1,5 & 0,5 & 0,5 & 0 & 0 & 1 & $\mathrm{~b}$ \\
\hline $10 \mathrm{~h} 00$ & 0 & 1 & 0 & 0 & 0 & 0 & 0 & $\mathrm{~b}$ \\
\hline $11 \mathrm{~h} 00$ & 0 & 0 & 0 & 0 & 0 & 0 & 0 & $\mathrm{~b}$ \\
\hline Média & $1,1 \mathrm{ab}$ & $3,3 \mathrm{ab}$ & $1,3 \mathrm{ab}$ & $1,8 \mathrm{ab}$ & $0,4 \mathrm{~b}$ & $2,1 \mathrm{ab}$ & $5,4 \mathrm{a}$ \\
\hline \\
Médias seguidas da mesma letra minúscula, na mesma linha, não diferem significativamente entre si pelo teste de \\
Tukey (5\%).
\end{tabular}

A segunda coleta de dados, provenientes do segundo plantio, ocorreu entre 15 e 18 de abril de 2014. Nesses dias, foram observadas principalmente abelhas africanizadas, da mesma forma que no primeiro plantio.

Nesses dias, abelhas Xylocopa sp. foram observadas coletando pólen nos pendões do milho, entretanto, foram visitas esporádicas. Outros insetos foram observados na cultura, mas sem se alimentar, nem coletar pólen

Com relação à frequência das abelhas africanizadas, nos diferentes híbridos, observou-se que essas abelhas preferiram coletar pólen no híbrido Viptera, comparado aos outros híbridos (Tabela 2).

Tabela 2. Número médio de abelhas Apis mellifera africanizadas, coletando pólen, das 7 h00 à 11h00, nos pendões de diferentes híbridos de milho (Zea mays L.), em Ribeirão Preto, SP, 2014.

\begin{tabular}{c|c|c|c|c|c|c|c|c|}
\hline Horário & Powercore & Viptera & $\begin{array}{c}\text { Optimu } \\
\mathbf{m}\end{array}$ & Herculex & $\begin{array}{c}\text { YG VT } \\
\text { PRO }\end{array}$ & $\begin{array}{c}\text { Viptera } \\
\mathbf{3}\end{array}$ & Convencional & Média \\
\hline $7 \mathrm{~h}-8 \mathrm{~h}$ & 10 & 35 & 4 & 6 & 5 & 25 & 10 & $13,57 \mathrm{a}$ \\
\hline $9 \mathrm{~h}-10 \mathrm{~h}$ & 7 & 38 & 8 & 12 & 9 & 11 & 8 & $13,28 \mathrm{a}$ \\
\hline Média & $8,5 \mathrm{bc}$ & $36,5 \mathrm{a}$ & $6 \mathrm{c}$ & $9 \mathrm{bc}$ & $7 \mathrm{bc}$ & $18 \mathrm{~b}$ & $9 \mathrm{bc}$ &
\end{tabular}

Médias seguidas da mesma letra minúscula, na mesma linha, não diferem significativamente entre si pelo teste de Tukey $(5 \%)$

Com relação ao teor de proteína bruta do pólen coletado pelas abelhas nos pendões, observou-se que o híbrido Viptera ${ }^{\circledR}$ apresentou teor de $24,79 \%$, em média significativamente maior $(\mathrm{F}=14,0029 * *$, $\mathrm{CV}=2,96)$, não diferindo apenas do híbrido Optimum®, com 23,16\% em média, mas diferindo dos demais híbridos de milho (Tabela 3).

Esses dados foram maiores comparados à Babendreier et al. (2004) que encontraram teor de 16,7\% de proteína bruta no pólen do milho coletado por abelhas A. melífera.

Quando comparados com os dados obtidos da frequência das abelhas nos pendões para coleta de pólen, observou-se que, no segundo plantio, o híbrido Viptera ${ }^{\circledR}$ foi o mais visitado e foi o que apresentou também o maior teor de proteína bruta $(24,79 \%)$ (Tabela 3). Entretanto, o híbrido Optimum ${ }^{\circledR}$ também apresentou alto teor de proteína bruta $(23,16 \%)$ e foi um dos híbridos menos visitados pelas abelhas.

Então, os híbridos apresentaram diferenças com relação à atratividade para as abelhas, em diferentes plantios, algumas vezes preferindo os híbridos convencionais, outras vezes, híbridos transgênicos. 
Tabela 3. Teor médio de proteína bruta (\%) do pólen de híbridos convencionais e transgênicos de milho (Zea mays), em Ribeirão Preto, SP, 2014.

\begin{tabular}{c|c}
\hline Híbridos & $\begin{array}{c}\text { Teor médio de proteína bruta } \\
(\boldsymbol{\%})\end{array}$ \\
\hline Viptera & $24,79 \mathrm{a}$ \\
\hline Optimum & $23,16 \mathrm{ab}$ \\
\hline Powercore & $21,79 \mathrm{bc}$ \\
\hline Convencional & $21,29 \mathrm{bc}$ \\
\hline Viptera 3 & $20,92 \mathrm{bc}$ \\
\hline YG & $20,13 \mathrm{c}$ \\
\hline Herculex & $20,11 \mathrm{c}$ \\
\hline Média Geral & 21,74 \\
\hline
\end{tabular}

Médias seguidas da mesma letra, na mesma coluna, não diferem significativamente entre si, pelo Teste de Tukey $(5 \%)$.

Neste experimento foi constatada a predominância da abelha Apis mellifera africanizada visitando os pendões do milho, nos dois plantios avaliados. Experimentos realizados na mesma área experimental, em anos anteriores (GONÇALVES, 2009; ROSA NETO, 2010, FACCIO, 2012), também relataram a predominância dessas abelhas coletando pólen nos pendões do milho, sendo 97,13\% em 2009 e 94,66\% em 2010, do total de insetos observados. De acordo com esses autores, outros insetos também visitaram os pendões do milho como abelhas Trigona spinipes (Hymenoptera: Apidae), Diabrotica speciosa (Coleoptera: Chrysomelidae), insetos da ordem Diptera e Lepidoptera e abelhas Tetragonisca angustula (Hymenoptera: Apidae).

As abelhas A. mellifera coletaram apenas pólen nas flores masculinas do milho, concordando com os dados de Gonçalves (2009), Rosa Neto (2010) e Malerbo et al. (2012). De acordo com esses autores, as abelhas aumentam sua frequência no decorrer do dia.

Com relação ao comportamento de forrageamento, a abelha A. mellifera, foi observada coletando pólen nas flores masculinas, nos pendões. A abelha aproximava-se do pendão, pousava sobre ele e, com o auxílio das peças bucais e pernas, retiravam o pólen. Posteriormente, a abelha transferia o recurso coletado para as corbículas. Além disso, foi observado durante a visita comportamento de limpeza do corpo, pernas e asas, armazenando o pólen nas corbículas. Ao final da coleta, as corbículas apresentavam-se repletas de pólen, com formato de esferas de cor amarelada.

Outro comportamento observado foi que a abelha ao coletar o pólen e movimentar as asas, ajudava na dispersão do pólen, sendo observada uma nuvem de pólen na saída da abelha.

De acordo com Malerbo (1987) as abelhas A. mellifera coletam pólen preferencialmente no período da manhã, entre $8 \mathrm{~h} 00$ e $10 \mathrm{~h} 00$.

Malerbo et al. (2012), estudando diferentes híbridos de milho, no mesmo local desse experimento, observou que o híbrido convencional foi significativamente mais atrativo para as abelhas comparado aos híbridos Cry 1A e Cry 1F, não diferindo apenas do híbrido Vip 3A.

Malone et al. (2001) e Huang et al. (2004) citaram que, aparentemente, as abelhas são incapazes de distinguir flores transgênicas de não transgênicas.

Ramirez-Romero et al. $(2005,2008)$ observaram alterações no comportamento das abelhas, verificando que levavam mais tempo a consumir a solução contaminada com pólen transgênico e que as abelhas reduziam o número de visitas a flores artificiais com uma solução açucarada contendo as proteínas sintetizadas pelo milho Bt, mantendo essa redução mesmo depois de lhes serem apresentadas as mesmas flores com alimento não contaminado, concluindo que a toxina Cry1 $\mathrm{Ab}$ possui um fator antinutricional ou repulsivo, com efeitos sub-letais que foram memorizados pelas abelhas. 
Com relação ao formato dos pendões foram observadas diferenças em alguns híbridos (Figura 1), sendo que o híbrido Optimum ${ }^{\circledR}$ apresentou o formato mais aberto em relação aos outros híbridos, com largura e altura superiores aos demais híbridos (Tabela 4). Nesse híbrido foi observado que as abelhas chegavam aos pendões, mas não pousavam para efetuar a coleta. Entretanto, novos experimentos devem ser realizados, pois os híbridos apresentam abertura das espiguetas para deiscência do pólen em períodos diferentes, o que pode ter sido a causa da ausência de abelhas nesse híbrido.

Tabela 4. Largura e altura $(\mathrm{em} \mathrm{cm}$ ) de pendões de diferentes híbridos de milho (Zea mays), em Ribeirão Preto,SP,2014.

\begin{tabular}{c|c|c}
\hline Híbridos & Largura (cm) & Altura (cm) \\
\hline Viptera & $12,2 \mathrm{c}$ & $29,8 \mathrm{~cd}$ \\
\hline Viptera 3 & $12,0 \mathrm{c}$ & $26,4 \mathrm{~d}$ \\
\hline YG VT PRO & $14,0 \mathrm{c}$ & $34,2 \mathrm{~b}$ \\
\hline Herculex HR & $17,2 \mathrm{bc}$ & $34,2 \mathrm{~b}$ \\
\hline Powercore & $19,6 \mathrm{bc}$ & $35,0 \mathrm{~b}$ \\
\hline Convencional & $24,2 \mathrm{~b}$ & $34,8 \mathrm{~b}$ \\
\hline Optimum Intrasect & $47,6 \mathrm{a}$ & $40,8 \mathrm{a}$
\end{tabular}

Médias seguidas pela mesma letra, na mesma linha ou na mesma coluna, não diferem significativamente entre si pelo teste de Tukey $(5 \%)$.

Figura 1. Formato dos pendões dos híbridos de milho (Zea mays) (A) Convencional, (B) Herculex, (C) Optimum, (D) Powercore, (E) Viptera, (F) Viptera 3 e (G) YG VT PRO, em Ribeirão Preto, SP, em 2014.
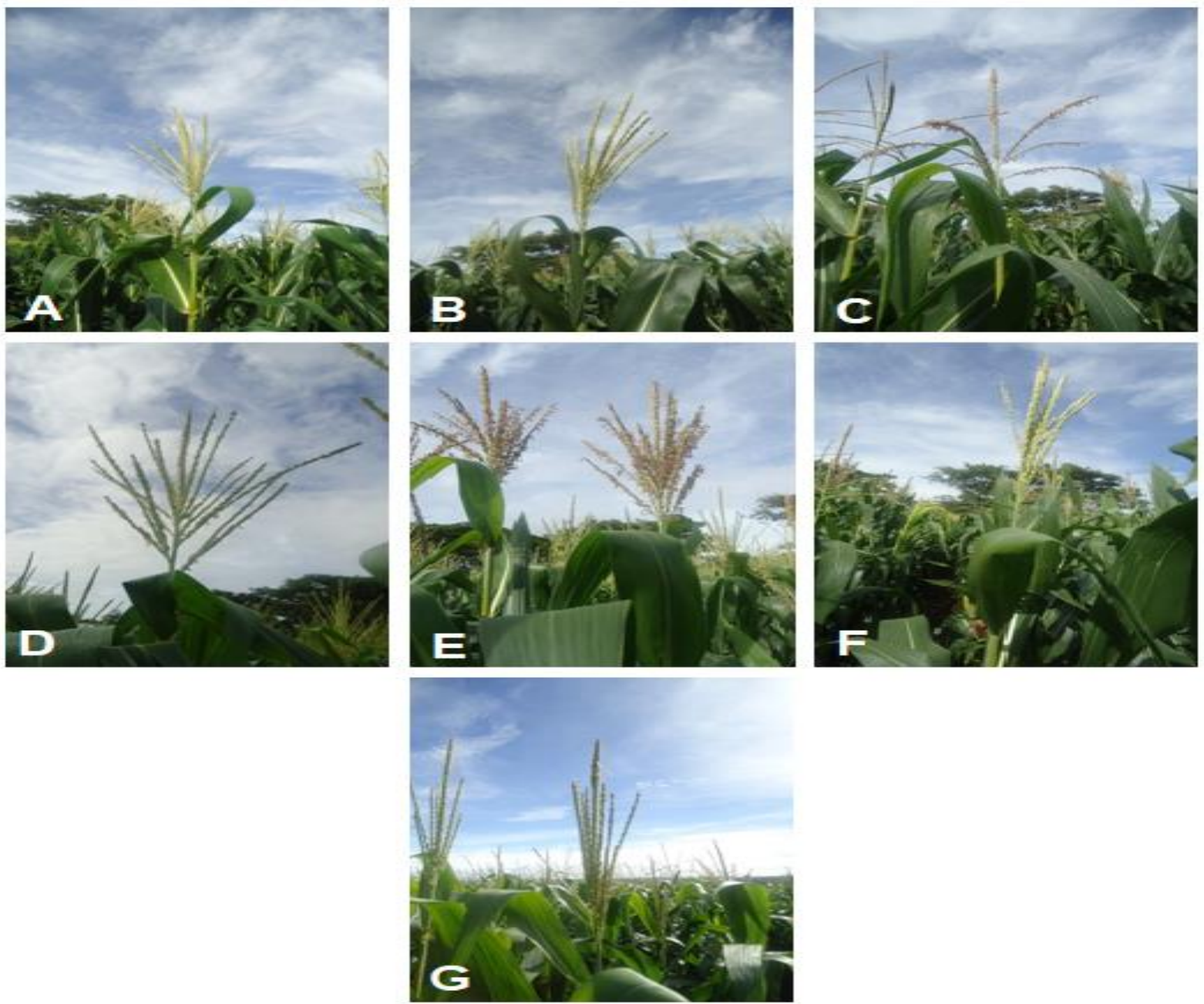
Com relação às espigas, também foram observadas diferenças, em especial com relação à coloração dos cabelos da espiga, sendo alguns híbridos mais avermelhados e outros amarelados.

Os grãos de pólen também apresentaram maiores diferenças com relação à coloração, e menores com relação ao formato (Figura 2).

Figura 2. Formato e coloração dos grãos de pólen dos híbridos de milho (Zea mays) (A) Convencional, (B) Herculex, (C) Optimum, (D) Powercore, (E) Viptera, (F) Viptera 3 e (G) YG VT PRO, em Ribeirão Preto, SP, em 2014.

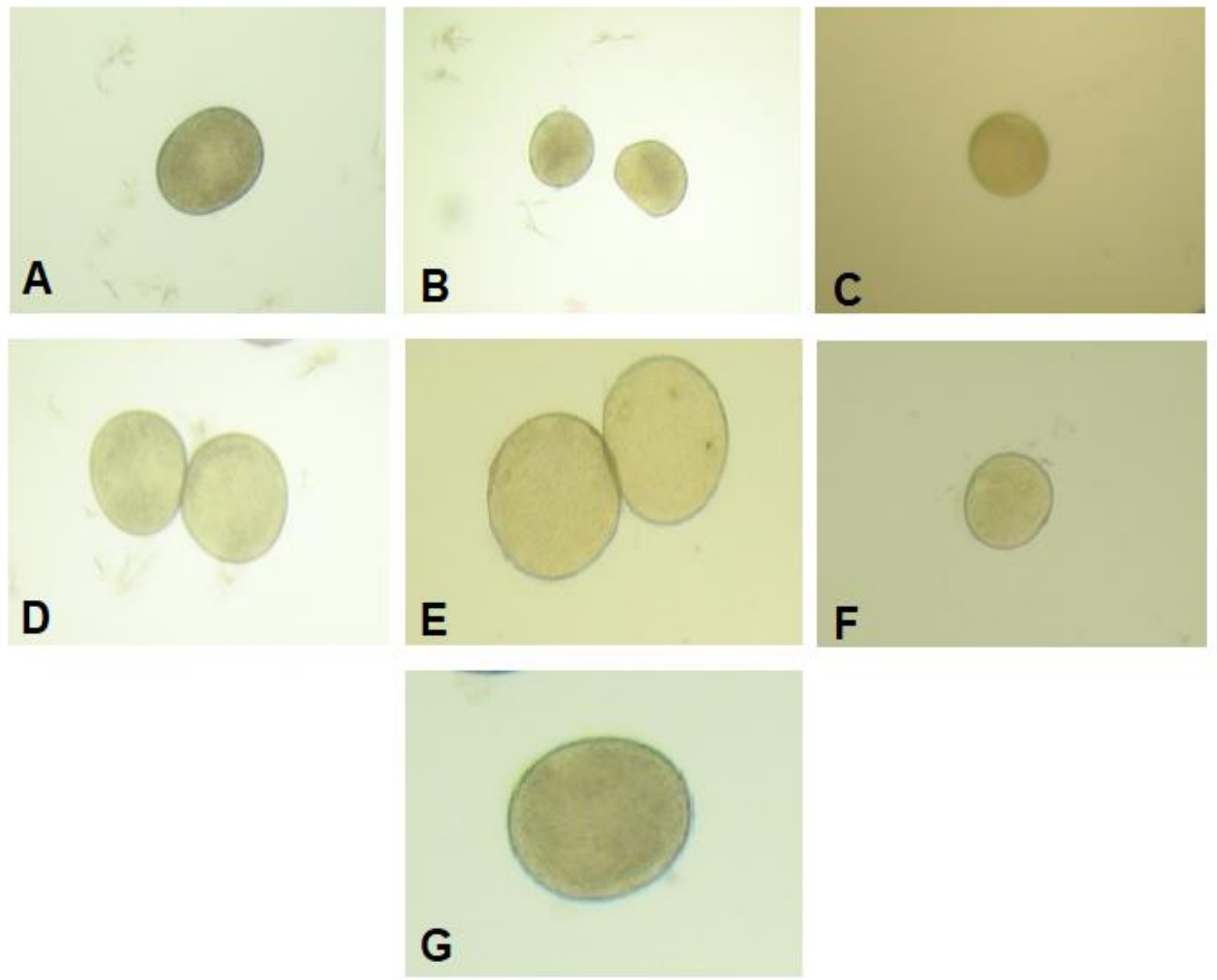

\section{CONCLUSÃO}

O híbrido mais visitado pelas abelhas africanizadas foi o Viptera, apresentando pólen com maior teor de proteína bruta e as menores medidas em altura e comprimento do pendão entre os híbridos avaliados.

\section{REFERÊNCIAS}

ARPAIA, S.et al. Non target and biodiversity impacts on pollinators and flowers visiting insects. In: Enviromental risk assessment of genetically modified organisms. Volume 2. Methodologies for assessing Bt cotton in Brazil. In: HILBECK, H.; ANDOW, D.A. FONTES, E.M.G. (Ed.).. Environmental risk assessment of genetically modified organisms: volume 2 - methodologies for assessing Bt cotton in Brazil. Wallingford: CABI, 2006. p.155-174. 
BABENDREIER, D.et al. Pollen consumption in honey bee larvae: a step forward in the risk assessment of transgenic plants. Apidologie, v. 35, p. 293-300, 2004.

GONÇALVES, F.M.M. O pólen do milho (Zea mays L. - Poaceae) como alimento protéico para as abelhas africanizadas Apis mellifera. Monografia. 35f. Graduação em Agronomia, Centro Universitário Moura Lacerda, Ribeirão Preto, 2009.

HUANG, Z.et al. Field and semifield evaluation of impacts of transgenic canola pollen on survival and development of worker bees. J. Econ. Entomol., v. 97, p. 1517-1523, 2004.

ISAAA. Global Status of Commercialized Biotech/GM Crops: 2016. ISAAA Brief No. 52. ISAAA: Ithaca, NY, 2016.

MALERBO, D.T.S. Levantamento da flora apícola nas proximidades do apiário do Campus de Jaboticabal e atividade de coleta das abelhas. Monografia. 35f. Graduação em Zootecnia, Faculdade de Ciências Agrárias e Veterinárias, Jaboticabal, 1987.

MALERBO-SOUZA, D. T.et al. Produção de Pólen em colmeias de abelhas Apis mellifera africanizadas no decorrer do ano, em Jaboticabal, SP, $19^{\circ}$ Congresso Brasileiro de Apicultura e $5^{\circ}$ Congresso Brasileiro de Meliponicultura, Anais [...] Gramado, RS, p. 51, 2012.

MIYAMOTO, I. Plantio de milho transgênico deve crescer 20\%. Disponível em: http://www.estadao.com.br/noticias/impresso,plantio-de-milho-transgenico-deve-crescer-20,699145,0.htm Acesso em: 26 set. 2012.

NOGUEIRA-COUTO, R. H.; COUTO, L.A. Apicultura: manejo e produtos. Jaboticabal: FUNEP, 191p, 2006.

RAMIREZ-ROMERO, R., CHAUFAU, J., PHAM-DELÈGUE, M. Effects of Cry1Ab protoxin, deltamethrin and imidacloprid on the foraging activity and the learning performances of the honeybee Apis mellifera, a comparative approach. Apidologie, v. 36, p. 601-611, 2005.

RAMIREZ-ROMERO, R.et al. Does Cry $1 \mathrm{Ab}$ protein affect learning performances of the honey bee Apis mellifera L. (Hymenoptera, Apidae)? Ecotox. Environ. Safety, v. 70, p. 327-333, 2008.

ROSA NETO, D. O pólen do milho (Zea mays L. - Poaceae) como alimento proteico para as abelhas. Monografia, Centro Universitário Moura Lacerda, Ribeirão Preto, SP. 2010. 35p.

SAS-Statistical Analisys System. System for microsoft windows. OnlineDoc® for Windows 9.3. Cary: Statistical Analysis System Institute, 2013.

WIESE, H. Apicultura: novos tempos. 2ed., Guaíba: Agrolivros, 2005. 378pp. 